\title{
PELATIHAN BANTUAN HIDUP DASAR BAGI ORANG AWAM DI ERA PANDEMI COVID-19
}

\author{
Zulmah Astuti $^{1^{*}}$, Misbah Nur Jannah ${ }^{2}$ \\ 1-2Universitas Muhammdiyah Kalimantan Timur \\ Email Korespondensi: za874@umkt.ac.id \\ Disubmit: 22 November 2021 Diterima: 12 Desember $2021 \quad$ Diterbitkan: 05 Februari 2022 \\ DOI: https://doi.org/10.33024/jkpm.v5i2.5521
}

\begin{abstract}
ABSTRAK
Henti Jantung tiba-tiba (Sudden Cardiac Arrest) yaitu berhentinya aktivitas jantung secara tiba-tiba dimana korban menjadi tidak berespon, tidak bernafas dan nadi tidak teraba. Angka keberlangsungan hidup pasien yang mengalami henti jantung di luar rumah sakit masih relatif rendah hal ini dikarenakan beberapa faktor diantaranya tempat kejadian sering terjadi di rumah dan sedikitnya orang yang mau melakukan terutama orang awam. Kondisi pandemic Covid 19 saat ini juga menambah alasan untuk seseorang enggan dan takut menolong orang yang mengalami henti jantung diluar rumah sakit. Berdasarkan hal tersebut maka diperlukan suatu pelatihan bantuan hidup dasar bagi orang awam baik pada kondisi biasa maupun pada saat pandemic. Metode pelaksanaan dilakukan melalui media zoom kepada 34 peserta pelatihan. Dari hasil kegiatan pelatihan bantuan hidup dasar ini didapatkan peningkatan pengetahuan sebelum dan sesudah pelatihan sebesar 76,3\%. Sedangkan keterampilan peserta dalam melakukan bantuan hidup dasar pada kasus henti jantung sebesar 93,4\%. Selain itu pelatihan ini juga menumbuhkan kepercayaan diri peserta dalam memberikan bantuan hidup dasar bahkan pada situasi pandemic Covid 19.
\end{abstract}

Kata Kunci: Henti Jantung, Bantuan Hidup Dasar (BHD), Pandemic Covid 19

\begin{abstract}
Sudden Cardiac Arrest is the sudden cessation of cardiac activity in which the victim becomes unresponsive, does not breathe and has no pulse. The survival rate of patients who experience cardiac arrest outside the hospital is still relatively low, this is due to several factors, including the place where the incident often occurs at home and the few people who want to do it, especially the lay rescuer. The current state of the Covid-19 pandemic also adds to the reasons why people are reluctant and afraid to help people who have cardiac arrest outside the hospital. Based on this, a basic life support training is needed for lay person both in ordinary conditions and during a pandemic. The implementation method was carried out through zoom media to 34 training participants. From the results of this basic life support training activity, it was found that the participants' knowledge and skills increased in performing basic life support in cases of cardiac arrest. In addition, this training also fosters participants' confidence in providing basic life support even in the Covid-19 pandemic situation.
\end{abstract}

Keywords: Cardiac Arrest, Basic Life Support (BHD), Pandemic Covid 19 


\section{PENDAHULUAN}

Penyakit kardiovaskular masih menjadi penyebab kematian utama di dunia yaitu mencapai mencapi 9 juta kasus pada tahun 2019 (Organization 2020). Angka prevalensi penyakit jantung di Indonesia pada tahun 2018 mencapai 1,5 \%, dimana Kalimantan timur utara (Kaltara) dan Kalimantan timur menempati urutan ke 1 dan ke 6 (Indonesia 2018). Penyakit kardiovaskular merupakan salah satu penyebab utama terjadinya Henti Jantung tiba-tiba (Sudden Cardiac Arrest) yaitu berhentinya aktivitas jantung secara tiba-tiba dimana korban menjadi tidak berespon, tidak bernafas dan nadi tidak teraba (Patil, Halperin et al. (2015); Patel. (2020)). Kebanyakan kasus henti jantung tiba-tiba $(80 \%)$ terjadi di luar rumah sakit yaitu di rumah dan di area fasilitas publik bersifat fatal apabila tidak ditangani segera (Patil, Halperin et al. (2015)). Angka keberlangsungan hidup pasien yang mengalami henti jantung di luar rumah sakit masih relative rendah hal ini dikarenakan beberapa faktor diantaranya tempat kejadian sering terjadi di rumah dan sedikitnya orang yang mau melakukan terutama orang awam (,Kwon, Jeon et al. (2019).

Berdasarkan hal tersebut maka The Interasional Liaison Committee on Resuscitation (ILCOR) memberikan formula untuk meningkatkan angka keberlangsungan hidup Pasien yang mengalami henti jantung di luar rumah sakit yaitu Panduan bantuan hidup dasar (BHD) berdasarkan ilmu pengetahuan tentang resusitasi, pendidikan yang efektif bagi orang awam dan petugas kesehatan, serta implementasi yang tepat terkait dengan rantai keberlangsungan hidup Pasien dengan henti jantung tiba tiba khusus nya di luar rumah sakit (Chain of survival of OCA) (Panchal, Bartos et al. 2020). Dengan banyaknya jumlah orang awam yang terlatih menggunakan paduan yang terstandar maka diharapkan terjadi peningkatan dalam angka keberlangsungan hidup pasien yang mengalami henti jantung tiba-tiba. Dengan banyaknya orang awam yang dapat melakukan Bantuan hidup dasar dapat meningkatkan angka keberlangsungan hidup pasien yang mengalami henti jantung di luar rumah sakit (Song, Guo et al. 2018).

Pada masa pandemic Covid saat ini, orang awam mungkin tidak memiliki alat pelindung diri yang adekuat saat memberikan pertolongan pada orang lain sehingga meningkatkan resiko terinfeksi COVID-19. Hal ini berdampak pada keengganan dalam menolong orang lain yang menunjukkan tanda henti jantung. Berdasarkan hal tersebut maka diperlukan pelatihan juga bagi orang awam bagaimana memberikan pertolongan bantuan hidup dasar di masa pandemic namun dengan tehnik yang dapat meminimalkan transmisi Covid19. Pelatihan ini berpedoman pada Panduan dari American Heart Association tahun 2020 yang menjelaskan bahwa orang awam dapat memberikan bantuan hidup dasar pada orang lain yang mengalami henti jantung dengan hanya memberikan kompresi dada (hands only CPR) dan penolong tetap menggunakan masker selama melakukan pertolongan. Adapun pasien yang mengalami henti jantung tetap dipakikan masker atau kain bersih untuk menutup area hidung dan mulut selama diberikan bantuan hidup dasar (Edelson, Sasson et al. 2020).

Pelaksanaan pelatihan bantuan hidup dasar di masa pandemic Covid 19 beralih dari pertemuan tatap muka kepada pertemuan dalam jaringan atau online meeting. Tentu saja hal ini hanya mampu memfasilitasi peserta pelatihan dalam segi pengetahuan saja sedangkan segi psikomotorik atau keterampilan tidak tercapai diperlukan suatu strategi agar aspek psikomotorik atau keterampilan dapt tercapai yaitu dengan melibatkan mahasiswa 
keperawatan dalam memberikan pelatihan kepada anggota keluarganya sendiri di rumah. Mahasiswa keperawatan terutama yang telah menempuh Pendidikan akademik dan masuk kedalam Pendidikan profesi telah dibekali dengan pelatihan yang lanjut terutama pertolongan pada kasus henti jantung melalui pelatihan basic trauma cardiac life support, sehingga dapat dianggap kompeten dalam pelaksanaan bantuan hidup dasar.

\section{MASALAH}

Alasan pengabdi melakukan pengabdian berupa pelatihan bantuan hidup dasar bagi orang awam adalah untuk meningkatkan pengetahuan dan keterampilan orang awam tentang bantuan hidup dasar pada kasus henti jantung diluar rumah sakit di masa pandemic. Adapun manfaat dari kegiatan pengabdian kepada masyarakat yang dilaksanakan ini adalah diharapkan memberikan dampak yang positif terutama untuk mengurangi angka mortalitas pasien dengan henti jantung di luar rumah sakit. Melalui artikel ini diharapkan dapat memberikan informasi bagi pengabdi lain untuk tetap dapat melakukan pengabdian kepada masyarakat meskipun ditengah pandemic karena hal ini berdampak besar bagi masyarakat terutama dalam melakukan pertolongan pertama pada kasus kegawatdaruratan sehari-hari.

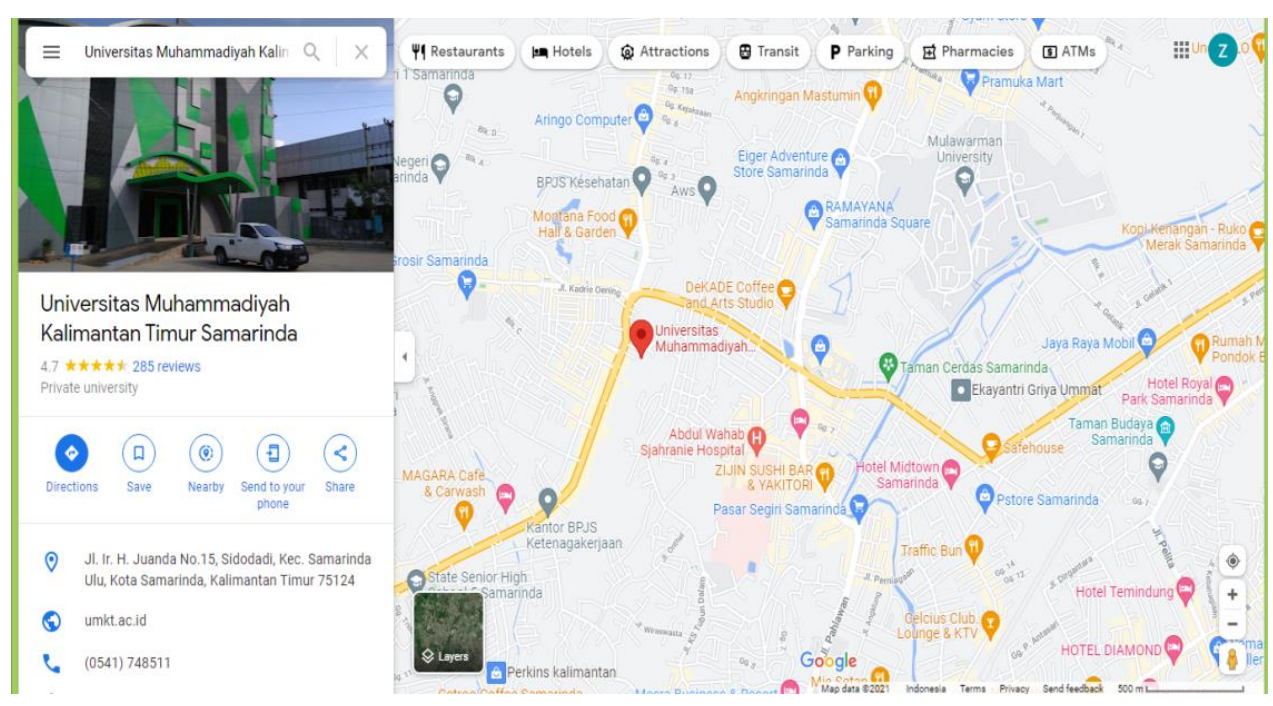

Gambar 1. Peta Lokasi Kegiatan Pengabdian Kepada Masyarakat

\section{METODE}

Kegiatan pengabdian kepada masyarakat di lakukan secara dalam jaringan/online dan luar jaringan/offline dalam satu waktu kegiatan kegiatan dalam jaringan yang melibatkan dosen dan mahasiswa dari profesi Ners UMKT. Waktu pelaksanaan pada tanggal 19 September 2021. Tahapan pelaksanaan adalah sebagai berikut :

\section{a. Tahapan Persiapan}

Tahapan persiapan yaitu pembuatan proposal pengabdian kepada masyarakat, pengarahan kepada mahasiswa terkait dengan persiapan peserta dan penyamaan persepsi tentang keterampilan bantuan hidup dasar bagi orang awam yang akan di ajarkan langsung oleh mahasisawa berdasarkan panduan yang telah dibuat. Persiapan media online yaitu 
melalui Zoom Meeting. Persiapan bahan materi yang berpedoman pada Panduan American Heart Association (AHA) tahun 2020 tentang bantuan hidup dasar pada orang awam dan bantuan hidup dasar pada situasi pandemic covid.

b. Tahapan pelaksanaan

Pengabdi membuka acara pelatihan dan menjelaskan tujuan dari diadakannya pelatihan BHD secara Online. Pemberian materi secara online disampaikan oleh pengabdi dengan durasi \pm 45 menit dan dlanjutkan dengan sesi tanya jawab peserta dan pengabdi. Tahapan selanjutnya adalah tahapan demonstrasi bantuan hidup dasar oleh seluruh mahasiswa di depan peserta pengabmas. Yang merupakan keluarga dekat dari mahasiswa itu sendiri. Seluruh peserta kemudian mempraktekkan apa yang telah diajarkan dan mahasiswa membantu menilai setiap aspek keterampilan menggunakan Checklist yang telah disediakan.

c. Tahap Terminasi

Sebelum kegiatan pengabdian berakhir, pengabdi memberikan kesempatan kepada peserta untuk menyampaikan pesan dan kesannya terhadap kegiatan pengabdian ini. Dari ketiga orang peserta menyatakan bahwa kegiatan ini sangat bermanfaat dan meningkatkan kepercayaan diri untuk menolong orang lain yang mengalami henti jantung. Kuesioner terkait pelaksanaan kegiatan di share kepada peserta untuk diisi sebagai bahan evaluasi pelaksaaan pengabdian kepada masyarakat kedepannya.

\section{HASIL DAN PEMBAHASAN}

Peserta pelatihan adalah orang awam yang merupakan anggota keluarga dari beberap Mahasiswa Ners UMKT yang telah menyetujui untuk mengikuti pelatihan BHD secara virtual melalui zoom. Yang berjumlah 34 orang peserta. Adapun data karakteristik peserta pengabdian yang dikumpulkan melaui google form adalah sebagai berikut:

Tabel 1. Data peserta berdasarkan jenis kelamin

\begin{tabular}{cccc} 
No & Jenis kelamin & frekuensi & persentase (\%) \\
\hline 1 & Laki-laki & 8 & 24 \\
\hline 2 & Perempuan & 26 & 76 \\
\hline & TOTAL & 34 & 100
\end{tabular}

Tabel 2. Data Peserta berdasarkan Usia menurut Depkes

\begin{tabular}{cccc} 
No & Rentang Usia & frekuensi & persentase $(\%)$ \\
\hline 1 & $<17$ tahun & 1 & 3 \\
\hline 2 & $17-25$ tahun & 14 & 41 \\
\hline 3 & $26-35$ tahun & 9 & 26 \\
\hline 4 & $36-45$ tahun & 1 & 3 \\
\hline 5 & $46-55$ tahun & 5 & 15 \\
\hline 6 & $56-65$ tahun & 4 & 12 \\
\hline & TOTAL & 34 & 100
\end{tabular}


Table 3. Data Peserta berdasarkan Jenis Pekerjaan

\begin{tabular}{cccc} 
No & Pekerjaaan & frekuensi & $\begin{array}{c}\text { persentase } \\
(\%)\end{array}$ \\
\hline 1 & PNS & 2 & 6 \\
\hline 2 & non pns/swasta & 4 & 12 \\
\hline 3 & Wiraswasta & 8 & 24 \\
\hline 4 & Ibu rumah tangga & 10 & 29 \\
\hline 5 & tidak bekerja & 3 & 9 \\
\hline 6 & Pelajar/mahasiswa & 5 & 15 \\
\hline 7 & Pensiunan & 2 & 6 \\
\hline & Total & 34 & 100
\end{tabular}

Berdasarkan tabel 1 didapatkan bahwa dari 34 peserta terbanyak adalah perempuan yaitu 26 orang peserta (76\%). Pada tabel 2 menunjukkan peserta terbanyak adalah dari rentang usia 17-25 tahun yaitu sejumlah 14 orang (41\%) pada usia ini adalah rentang usia remaja akhir. Terdapat 4 peserta yang masuk dalam rentang usia lansia akhir. Berdasarkan tabel 3 didapatkan jenis pekerjaan peserta terbanyak adalah Ibu Rumah tangga. Yaitu sebanyak 10 orang (29\%) diikuti pekerjaan wiraswasta sebanyak 8 orang (24\%).

Dilakukan penilaian rata-rata peningkatan pengetahuan dan keterampilan peserta tentang tindakan BHD dengan hasil sebagai berikut :

Tabel 4. Rata-rata peningkatan Pengetahuan

Rata-rata Min Max Median

\begin{tabular}{ccccc} 
Nilai & & & & \\
\hline Pretest & 42.35 & 30 & 60 & 40 \\
\hline Postest & 76.76 & 60 & 90 & 80 \\
\hline
\end{tabular}

(Sumber : data primer, 2021)

Tabel 5. Keterampilan BHD

\begin{tabular}{cccc} 
tindakan & ya & tidak & Rata-rata \\
\hline Melakukan 3A & 32 & 2 & $94 \%$ \\
\hline Memeriksa kesadaran & 32 & 2 & $94 \%$ \\
\hline Memeriksa pernafasan & 32 & 2 & $94 \%$ \\
\hline Memanggil bantuan & 33 & 1 & $97 \%$ \\
\hline $\begin{array}{c}\text { Melakukan kompresi dada } \\
\text { a. Meletakkan tangan di tengah dada } \\
\text { b. Menekan dada dengan keras dan dalam }\end{array}$ & 30 & 4 & $88 \%$ \\
\hline
\end{tabular}

(Sumber : data primer, 2021)

Diakhir kegiatan pengabdian kepada masyarakat, peserta diminta untuk mengisi kuesioner terkait dengan pelaksanaan kegiatan melalui google form didapatkan data sebagai berikut : 
Tabel 6. Data hasil Kuesioner

\begin{tabular}{clcccc}
\multirow{2}{*}{ No } & \multicolumn{1}{c}{ Pernyataan } & \multicolumn{3}{c}{ Respon } \\
\cline { 2 - 6 } & $\begin{array}{l}\text { Sangat } \\
\text { setuju }\end{array}$ & $\%$ & Setuju & $\%$ \\
\hline $1 \quad \begin{array}{l}\text { Pelatihan tentang bantuan hidup dasar } \\
\text { ini sangat berguna }\end{array}$ & 32 & 94 & 2 & 6 \\
\hline $\begin{array}{l}\text { Materi yang disampaikan oleh pemateri } \\
\text { menarik dan mudah di pahami }\end{array}$ & 29 & 85 & 5 & 15 \\
\hline$\quad \begin{array}{l}\text { langkah langkah pelaksanaan Bantuan } \\
\text { hidup dasar mudah diikuti }\end{array}$ & 25 & 74 & 9 & 26 \\
\hline $\begin{array}{l}\text { Kegiatan pelatihan seperti saat ini } \\
\text { perlu sering diadakan }\end{array}$ & 29 & 85 & 5 & 15 \\
\hline $5 \quad \begin{array}{l}\text { Saya memiliki kepercayaan diri untuk } \\
\text { menolong orang yang henti jantung }\end{array}$ & 27 & 79 & 7 & 21 \\
\hline
\end{tabular}

Berdasarkan tabel 4 didapatkan hasil bahwa sebagian besar peserta menyatakan sangat setuju (94\%) bahwa pelatihan BHD ini sangat berguna. Sebagian besar peserta (79\%) juga menyatakan bahwa setelah mengikut pelatihan ini memiliki kepercayaan diri untuk menolong pasien atau korban dengan henti jantung.

Kegiatan pengabdian ini juga relevan untuk dilaksanakan pada kondisi pandemic covid dan memberikan dampak bagi peningkatan pengetahuan peserta pengabdian tentang bantuan hidup dasar. Pelaksanaan menggunakan media seperti zoom bermanfaat agar proses pembelajaran dan pelatihan tetap berjalan meskipun ditengah situasi pandemic covid (Purba, Siregar et al. 2020). Pemanfaatan media zoom sebagai media pelatihan dalam kegiatan ini terbukti efektif dalam penyampaian pengetahuan tentang bantuan hidup dasar. Hal ini sejalan dengan penelitian yang dilakukan oleh Yudha (2021) yang menyatakan bahwa pelatihan bantuan hidup dasar secara virtual terbukti memberikan pengaruh terhadap peningkatan pengetahuan peserta tentang bantuan hidup dasar. Pelatihan BHD dimasa pandemic melalui virtual memang dapat menjadi alternative untuk mengurangi kontak dengan banyak orang, namun dari segi kelemahannya adalah keterampilan peserta belum terukur dengan baik karena alat peraga yang digunakan tidak menggunakan panthom CPR. Hal ini sejalan dengan penelitian yang disampaikan oleh Nugroho (2021) yang juga melaksanakan pelatihan BHD melalui media Zoom menyatakan bahwa cara ini memiliki dampak positif terhadap pengetahuan peserta dan meminimalisir pertemuan dengan banyak orang, namun memiliki kekurangan dalam melakukan penilaian terhadap keterampilan peserta.

Penelitian yang dilakukan oleh Aswad, Luawo et al. (2021) yang melakukan pelatihan BHD secara langsung kepada peserta menyatakan bahwa pada pelaksanaannya memang dapat mengukur pengetahuan dan keterampilan dengan baik namun sulit untuk menjaga protocol kesehatan antar peserta dan pengabdi pada saat sesi keterampilan. Dalam kegiatan ini untuk memaksimalkan pengajaran keterampilan BHD pada peserta, maka mahasiswa Ners diminta untuk mencontohkan langsung didepan peserta bagaimana langkah-langkah BHD sesuai dengan Panduan yang telah ada. Salah satu kelemahan yang terjadi dalam pembelajaran atau pelatihan melalui media online adalah sulit untuk menjaga fokus peserta pelatihan. Hal ini juga dinyatakan oleh Murniati and Rahmah (2021) yang menyatakan bahwa peserta cenderung tidak fokus pada saat pelaksanaan zoom. Untuk mengurangi ketidakfokusan peserta dalam hal ini pengabdi melakukan Tanya jawab dan 
apersepsi selama pemberian materi dengan peserta dengan tujuan untuk mengembalikan fokus mereka.

Melalui kegiatan yang telah dilaksanakan ini diharapkan dapat memberikan manfaat terutama bagi peserta karena memperoleh pengetahuan dan keterampilan tentang bantuan hidup dasar pada henti jantung diluar rumah sakit. Harapannya dengan banyaknya orang awam yang telah mengikuti pelatihan bantuan hidup dasar maka angka mortalitas pasien dengan henti jantung terutama diluar rumah sakit dapat menurun.

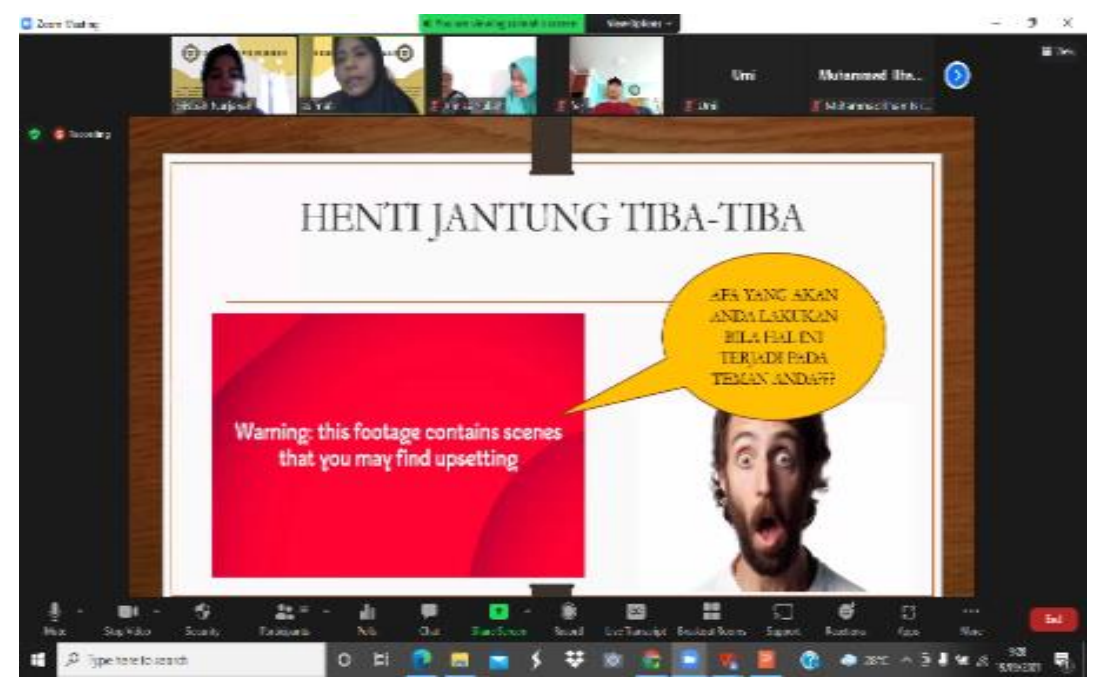

Gambar 2. Foto kegiatan PKM

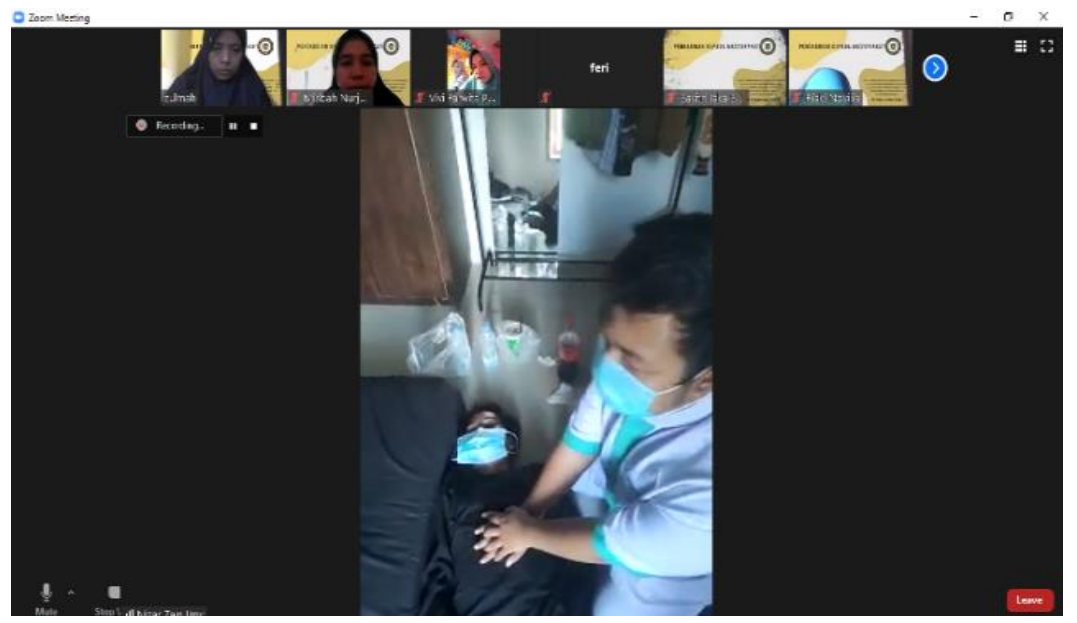

Gambar 3. Foto kegiatan PKM

\section{KESIMPULAN}

Kegiatan pengabdian kepada masyarakat berupa pelatihan bantuan hidup dasar (BHD)bagi orang awam dimasa pandemic yang dilaksanakan melalui media Zoom pada 34 orang peserta. Kegiatan ini dibantu oleh mahasiswa Ners yang juga merupakan anggota keluarga dari para peserta. Tujuan kegiatan ini yaitu untuk meningkatkan pengetahuan tentang BHD dicapai melalui pemberian materi oleh pengabdi secara online. Hasil dari kegiatan ini adalah terjadi peningkatan pengetahuan peserta tentang BHD. Adapun tujuan untuk 
meningkatkan keterampilan melaksanakan BHD adalah dengan mengarahkan mahasiswa Ners yang sebelumnya sudah pernah mengikuti pelatihan Basic Trauma Cardiac Life Support untuk langsung memperagakan langkah-langkah BHD di depan peserta masing-masing dan selanjutnya akan disimulasikan oleh seluruh peserta. Beberapa kelemahan dalam kegiatan ini adalah beberapa peserta tidak fokus dalam mendengarkan materi yang disampaikan. Secara umum kegiatan ini telah dapat dilaksanakan dengan baik dan memberikan manfaat bagi peningkatan pengetahuan peserta tentang bantuan hidup dasar.

\section{DAFTAR PUSTAKA}

Aswad, Y., et al. (2021). "Peningkatan Pengetahuan dan Keterampilan Karang Taruna melalui Pelatihan Bantuan Hidup Dasar (CPR) pada Masa Pandemi Covid-19 di Kecamatan Kota Utara, Kota Gorontalo." Jurnal Abdidas 2(1): 81-85.

Edelson, D. P., et al. (2020). "Interim guidance for basic and advanced life support in adults, children, and neonates with suspected or confirmed COVID-19: from the emergency cardiovascular care committee and get with the guidelines-resuscitation adult and pediatric task forces of the American Heart Association." Circulation 141(25): e933-e943.

Indonesia, K. K. R. (2018). "Hasil Utama RISKESDAS 2018. Badan Penelitian dan Pengembangan Kesehatan."

Kwon, J.-m., et al. (2019). "High incidence and mortality of out-of-hospital cardiac arrest on traditional holiday in South Korea." Korean circulation journal 49(10): 945-956.

Murniati, N. and R. O. Rahmah (2021). "Efektivitas Pendidikan Dan Pelatihan Pegawai Pada Masa Pandemi Covid-19 Di Rumah SakiT ABC." Jurnal Administrasi Bisnis Terapan 3(2).

Nugroho, K. (2021). "Pelatihan Bantuan Hidup Dasar Bagi Siswa SMA 1 Sumber Pucung Kabupaten Malang." Jurnal Pengabdiaan Masyarakat Kasih (JPMK) 2(2): 64-69.

Organization, W. H. (2020). "WHO reveals leading causes of death and disability worldwide: 2000-2019."

Panchal, A. R., et al. (2020). "Part 3: adult basic and advanced life support: 2020 American Heart Association guidelines for cardiopulmonary resuscitation and emergency cardiovascular care." Circulation 142(16_Suppl_2): S366S468.

Patel., K., \& Hipskind., E., J (2020). "Cardiac Arrest; NCBI."

Patil, K. D., et al. (2015). "Cardiac arrest: resuscitation and reperfusion." Circulation research 116(12): 2041-2049.

Purba, R., et al. (2020). "Pembelajaran Berbasis Google Classroom, Geoogle Meet dan Zoom Guru SMP Negeri 2 Batubara." BERNAS: Jurnal Pengabdian Kepada Masyarakat 1(4): 410-416.

Song, J., et al. (2018). "The effect of bystander cardiopulmonary resuscitation on the survival of out-of-hospital cardiac arrests: a systematic review and meta-analysis." Scandinavian journal of trauma, resuscitation and emergency medicine 26(1): 1-10.

Yudha, G. K. E. (2021). Pengaruh Latihan Resusitasi Jantung Paru Secara Virtual Terhadap Tingkat Pengetahuan Pada Remaja Di Sman 3 Singaraja, Stikes Bina Usada Bali. 